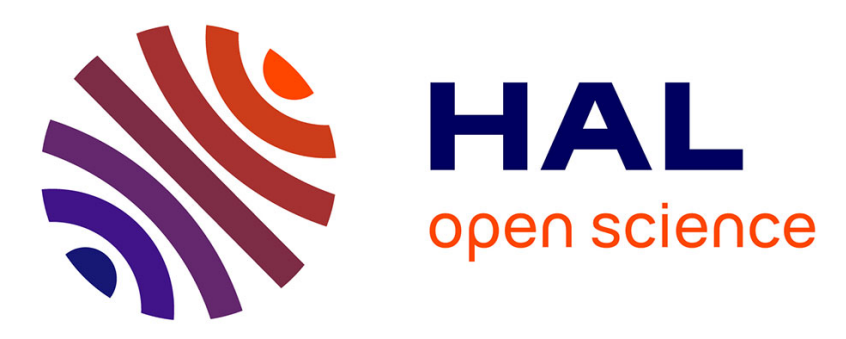

\title{
Composition dependence of spin transition in $(\mathrm{Mg}, \mathrm{Fe}) \mathrm{SiO} 3$ bridgmanite
}

\author{
Susannah Dorfman, James Badro, Jean-Pascal Rueff, Paul Chow, Yuming \\ Xiao, Philippe Gillet
}

\section{- To cite this version:}

Susannah Dorfman, James Badro, Jean-Pascal Rueff, Paul Chow, Yuming Xiao, et al.. Composition dependence of spin transition in ( $\mathrm{Mg}, \mathrm{Fe}) \mathrm{SiO} 3$ bridgmanite. American Mineralogist, 2015, 100 (10), pp.2246-2253. 10.2138/am-2015-5190 . insu-02913653

\section{HAL Id: insu-02913653 \\ https://hal-insu.archives-ouvertes.fr/insu-02913653}

Submitted on 11 Aug 2020

HAL is a multi-disciplinary open access archive for the deposit and dissemination of scientific research documents, whether they are published or not. The documents may come from teaching and research institutions in France or abroad, or from public or private research centers.
L'archive ouverte pluridisciplinaire HAL, est destinée au dépôt et à la diffusion de documents scientifiques de niveau recherche, publiés ou non, émanant des établissements d'enseignement et de recherche français ou étrangers, des laboratoires publics ou privés. 
Revision 1

\title{
Composition dependence of spin transition in $(\mathrm{Mg}, \mathrm{Fe}) \mathrm{SiO}_{3}$ bridgmanite
}

Susannah M. Dorfman ${ }^{1}$, James Badro ${ }^{1,2}$, Jean-Pascal Rueff ${ }^{3}$, Paul Chow ${ }^{4}$, Yuming Xiao ${ }^{4}$, Philippe Gillet ${ }^{1}$

1: Earth and Planetary Science Laboratory, Ecole polytechnique fédérale de Lausanne, Station 3, CH-1015 Lausanne, Switzerland

2: Institut de Physique du Globe de Paris, Sorbonne Paris Cité - Université Paris Diderot, UMR CNRS 7154, 75005 Paris, France

3: Synchrotron SOLEIL, L'Orme des Merisiers, BP 48 Saint-Aubin, 91192 Gif-sur-Yvette, France

4: HPCAT, Geophysical Laboratory, Carnegie Institution of Washington, Argonne, Illinois 60439, USA

\begin{abstract}
Spin transitions in $(\mathrm{Mg}, \mathrm{Fe}) \mathrm{SiO}_{3}$ bridgmanite have important implications for the chemistry and dynamics of Earth's lower mantle, but have been complex to characterize in experiments. We examine the spin state of Fe in highly Fe-enriched bridgmanite synthesized from enstatites with measured compositions $\left(\mathrm{Mg}_{0.61} \mathrm{Fe}_{0.38} \mathrm{Ca}_{0.01}\right) \mathrm{SiO}_{3}$ and $\left(\mathrm{Mg}_{0.25} \mathrm{Fe}_{0.74} \mathrm{Ca}_{0.01}\right) \mathrm{SiO}_{3}$. Bridgmanite was synthesized at 78-88 GPa and 1800-2400 K and X-ray emission spectra were measured on decompression to 1 bar (both compositions) and compression to $126 \mathrm{GPa}$
\end{abstract}


$\left(\left(\mathrm{Mg}_{0.61} \mathrm{Fe}_{0.38} \mathrm{Ca}_{0.01}\right) \mathrm{SiO}_{3}\right.$ only) without additional laser heating. Observed spectra confirm that $\mathrm{Fe}$ in these bridgmanites is dominantly high spin in the lower mantle. However, the total spin moment begins to decrease at $\sim 50 \mathrm{GPa}$ in the $74 \% \mathrm{FeSiO}_{3}$ composition. These results support density functional theory predictions of a lower spin transition pressure in highly Fe-enriched bridgmanite and potentially explain the high solubility of $\mathrm{FeSiO}_{3}$ in bridgmanite at pressures corresponding to Earth's deep lower mantle.

Keywords: bridgmanite; spin transition; iron-bearing silicates; lower mantle

\section{Introduction}

Iron is the Earth's most abundant transition metal and its different electronic states have been of great interest for their possible effects on mantle seismic velocities, rheology, transport properties and chemical reactions (Lin et al. 2013). A pressure-induced spin-pairing transition has been identified in $(\mathrm{Mg}, \mathrm{Fe}) \mathrm{O}$ magnesiowüstite at lower mantle conditions by both experimental and theoretical methods (e.g. Badro et al. 2003; Speziale et al. 2005; Tsuchiya et al. 2006). The transition increases density, incompressibility, shear modulus, elastic anisotropy, electrical conductivity, and iron partitioning into $(\mathrm{Mg}, \mathrm{Fe}) \mathrm{O}$ and decreases thermal conductivity and bulk sound speed (Lin et al. 2013). Spin transitions in the dominant phase of the lower mantle, perovskite-structured $(\mathrm{Mg}, \mathrm{Fe}, \mathrm{Al})(\mathrm{Fe}, \mathrm{Al}, \mathrm{Si}) \mathrm{O}_{3}$, recently named bridgmanite, potentially have even greater impact on mantle properties. However, incorporation of $\mathrm{Fe}$ in bridgmanite is more complex and identification of spin transition(s) has been ambiguous.

In bridgmanite, ferrous iron $\left(\mathrm{Fe}^{2+}\right)$ substitutes for $\mathrm{Mg}$ in the larger, pseudo-dodecahedral A site, while ferric iron $\left(\mathrm{Fe}^{3+}\right)$ can enter both the $\mathrm{Mg}$-site and the octahedral B site. At ambient conditions, both species and sites are in the high-spin (unpaired electrons) state. Pressure- 
induced spin transitions in bridgmanite were first identified at 70 and $120 \mathrm{GPa}$ by X-ray emission spectroscopy (XES) (Badro et al. 2004) and time-domain synchrotron Mössbauer spectroscopy (T-SMS) (Jackson et al. 2005). These transitions were suggested to represent changes of high-spin iron to low spin (all electrons paired) (e.g. Badro et al. 2004; Lin et al. 2010a; McCammon et al. 2010), mixed spin (for different Fe atoms, all or no electrons paired) (e.g. Badro et al. 2004; Catalli et al. 2010) or intermediate spin (some electrons paired) (Lin et al. 2008; McCammon et al. 2008). Studies have since reported a wide range of sharp or gradual transitions in bridgmanite for different compositions, experimental conditions and techniques (Table 1). Changes in the compressibility and electrical conductivity of Fe-bearing bridgmanite at high pressure have also been linked to these spin transitions (Catalli et al. 2010, 2011; Ohta et al. 2010; Mao et al. 2011; Boffa Ballaran et al. 2012).

Recent density functional theory (DFT) calculations (Umemoto et al. 2008; Bengtson et al. 2009; Hsu et al. 2010, 2011; Hsu and Yu 2012) have offered insights important to the interpretation of experiments on spin transitions in bridgmanite. Unlike experiments, DFT methods are not limited in accessible conditions and allow full control of parameters such as the valence state of iron. DFT calculations have determined that both ferrous and ferric iron in the pseudododecahedral site remain in the high-spin state throughout the pressure-temperature range of the Earth's lower mantle (Hsu et al. 2010, 2011). However, ferric iron in the B site will undergo a high-to-low spin transition (Hsu et al. 2011). Theoretical calculations do not support the stability of an intermediate spin state (Hsu et al. 2010).

$(\mathrm{Mg}, \mathrm{Fe}) \mathrm{SiO}_{3}$ bridgmanites were recently synthesized at deep mantle pressures with as much as $75 \% \mathrm{FeSiO}_{3}$, higher than previous estimates of the maximum solubility of the $\mathrm{FeSiO}_{3}$ component (Tateno et al. 2007; Dorfman et al. 2013). Whether an increase in Fe-solubility in bridgmanite 
near 60-70 GPa is related to spin transitions is unknown. Increasing Fe-content has been observed to increase the spin transition pressure in (Mg,Fe)O (Fei et al. 2007). While earlier DFT studies predicted a higher spin transition pressure with increasing $\mathrm{Fe}$-content in $(\mathrm{Mg}, \mathrm{Fe}) \mathrm{SiO}_{3}$ bridgmanite (Cohen et al. 1997; Stackhouse et al. 2007), more recent studies have predicted that the spin transition pressure decreases strongly with $\mathrm{Fe}$-content for $(\mathrm{Mg}, \mathrm{Fe}) \mathrm{SiO}_{3}$ bridgmanite with $>25 \% \mathrm{FeSiO}_{3}$ (Bengtson et al. 2008; Umemoto et al. 2008). The key difference in the more recent studies is the structure of the low-spin bridgmanite, which is predicted (Bengtson et al. 2009; Hsu et al. 2010; Umemoto et al. 2010; Caracas et al. 2014) and recently observed (Caracas et al. 2014) to be slightly distorted relative to the high-spin structure. A decrease in spin transition pressure would suggest that $\mathrm{Fe}^{2+}$ could adopt a low spin state in bridgmanite in highly Fe-rich heterogeneities in Earth's deep lower mantle.

A key technique for investigating spin states of transition metals is X-ray emission spectroscopy (XES) (Rueff et al. 1999; Badro et al. 2003, 2004). XES detects exchange interactions between $3 p$ and $3 d$ orbitals (Peng et al. 1994; Mattila et al. 2007). These energies are sensitive to multiple aspects of the electronic environment of Fe, including bonding, coordination, valence and spin states. The energy multiplets cluster to form a main $\mathrm{K} \beta_{1,3}$ peak and a lower energy $\mathrm{K} \beta$ ' satellite. Spin transitions are identified and quantified by analysis of energy shift of the $K \beta_{1,3}$ peak and intensity of the $\mathrm{K} \beta$ ' satellite relative to well-characterized standards (Vankó et al. 2006). In this study we examine the effects of composition on electronic spin of $(\mathrm{Mg}, \mathrm{Fe}) \mathrm{SiO}_{3}$ bridgmanite by applying XES to bridgmanites with $38 \%$ and $74 \% \mathrm{FeSiO}_{3}$.

\section{Methods}


Starting materials were natural enstatites of compositions $\left(\mathrm{Mg}_{0.61} \mathrm{Fe}_{0.38} \mathrm{Ca}_{0.01}\right) \mathrm{SiO}_{3}(\mathrm{Fe} \# 38)$ and $\left(\mathrm{Mg}_{0.25} \mathrm{Fe}_{0.74} \mathrm{Ca}_{0.01}\right) \mathrm{SiO}_{3}(\mathrm{Fe \# 74})$. Additional details on these samples are given by Dorfman et al. (2013). Mössbauer spectroscopy of starting materials on a ${ }^{57}$ Co source at sector 3 of the Advanced Photon Source confirmed no measurable ferric iron. Enstatite powder and $\mathrm{NaCl}$ pressure-transmitting medium were dried in a furnace at $120^{\circ} \mathrm{C}$ overnight before loading. Samples were loaded in a sandwich configuration between $\mathrm{NaCl}$ platelets in diamond anvil cells with $150-\mu \mathrm{m}$ culet $(300-\mu \mathrm{m}$ bevel). X-ray transparent beryllium gaskets were preindented to 20 $25-\mu \mathrm{m}$ thickness with $50-\mu \mathrm{m}$ diameter sample chambers. Pressures were determined from the edge of the diamond Raman peak recorded from the tip of the anvil at the sample position (Akahama and Kawamura 2006). This measurement has an estimated uncertainty of $~ 3 \%$.

To transform starting materials to the bridgmanite phase, samples were pressurized to $78-88 \mathrm{GPa}$ and heated from both sides to $1800-2400 \mathrm{~K}$ with a near-infrared laser. Complete transformation was confirmed by X-ray diffraction (XRD) at beamline 13-ID-D (GSECARS sector) of the Advanced Photon Source (APS) or beamline ID27 of the European Synchrotron Radiation Facility (ESRF). Observed diffraction patterns are consistent with previous measurements of bridgmanites synthesized from these compositions (Figure 1) (Dorfman et al. 2013). Minor amounts of $\mathrm{CaCl}_{2}$-type $\mathrm{SiO}_{2}$ were also observed but diffraction patterns show no $(\mathrm{Mg}, \mathrm{Fe}) \mathrm{O}$ or $\mathrm{Fe}$ metal.

XES was performed at beamline 16-ID-D (HPCAT sector) of the APS (Bradley et al. 2012) or beamline GALAXIES of Synchrotron SOLEIL (Rueff et al. 2015). At 16-ID-D, the beam size was $35 \times 55 \mu \mathrm{m}$, incident energy was $11.3 \mathrm{keV}$, and typical count rate was $60 \mathrm{cts} / \mathrm{s}$. Incident $\mathrm{X}$ rays passed through one diamond anvil, and emission was measured through the beryllium gasket (Figure 2a). At GALAXIES, the beam size was 30x80 $\mu \mathrm{m}$, incident energy was $10 \mathrm{keV}$ 
and typical count rates were $70-150 \mathrm{cts} / \mathrm{s}$. Emission signal was maximized at GALAXIES by collecting spectra at an angle minimizing the path through the beryllium gasket (Figure 2b). For each sample, pressure was increased or decreased from the synthesis pressure without additional laser heating or annealing. Spectra were recorded from 1 bar-126 $\mathrm{GPa}$ for $\left(\mathrm{Mg}_{0.61} \mathrm{Fe}_{0.38} \mathrm{Ca}_{0.01}\right) \mathrm{SiO}_{3}$ composition and 1 bar-88 $\mathrm{GPa}$ for $\left(\mathrm{Mg}_{0.25} \mathrm{Fe}_{0.74} \mathrm{Ca}_{0.01}\right) \mathrm{SiO}_{3}$ composition.

After the XES compression experiment on the Fe\#38 sample, energy-domain synchrotron Mössbauer spectroscopy was performed at beamline ID18 of the ESRF (Rüffer and Chumakov 1996). The Mössbauer source was a ${ }^{57} \mathrm{FeBO}_{3}$ single crystal oscillated in a sinusoidal profile (Potapkin et al. 2012). Source velocity was calibrated by a natural Fe foil. The linewidth of the source was calibrated by a $\mathrm{K}_{2} \mathrm{Mg}^{57} \mathrm{Fe}(\mathrm{CN})_{6}$ single-line absorber. The X-ray beam was focused to 9x $14 \mu \mathrm{m}$. A spectrum was obtained for the natural sample at $126 \mathrm{GPa}$ in $\sim 18$ hours.

\section{Results}

For all Fe-rich bridgmanite samples at all conditions, XES profiles fall between the high- and low-spin references (Figure 3). The intensity of the $\mathrm{K} \beta$ ' satellite peak decreases with pressure. On decompression, the intensity of the $\mathrm{K} \beta$ ' satellite peak increases but remains weaker than the high-spin references at ambient conditions (Figure 3a,b). The difference between the ambient and $~ 80 \mathrm{GPa}$ spectra is greater for Fe\#74 composition than for the Fe\#38 composition. On increasing pressure from $78-126$ in the Fe\#38 composition, $\mathrm{K} \beta$ ' intensity also decreases subtly but systematically (Figure 3c). At all pressures $\mathrm{K} \beta$ ' is observed to be greater than the low-spin reference. These observations are consistent with a gradual, incomplete spin transition and/or pressure-induced broadening (Lin et al. 2013). 
To distinguish the effects of spin state and pressure, the total spin moment was determined from differences between spectra and standards. Reference spectra used in this study are XES for $\left(\mathrm{Mg}_{0.75} \mathrm{Fe}_{0.25}\right) \mathrm{O}$ at ambient conditions (high spin) and $90 \mathrm{GPa}$ (low spin) observed at HPCAT, APS (Lin et al. 2010b). These spectra have been used as references in previous studies of Febearing bridgmanite and post-perovskite (Mao et al. 2010, 2011). The width of the K $\beta$ peak measured for bridgmanite at GALAXIES, SOLEIL is similar to the reference spectra. The broader K $\beta$ peak measured for bridgmanite and high-spin reference at HPCAT, APS may be due to differences in beamline configuration or background from the Be gasket in the $90^{\circ}$ geometry (Figure 2). To confirm that these references are comparable to our data, we also consider Febearing silicates, almandine glass and enstatite, as secondary high-spin references. These samples were loaded in diamond anvil cells with Be gaskets and measured at ambient conditions at HPCAT and GALAXIES, respectively. The secondary high-spin references overlap with highspin $(\mathrm{Mg}, \mathrm{Fe}) \mathrm{O}$ up to at least $7056 \mathrm{eV}$ (Figure 3).

Although the secondary references suggest the beamline configurations in these experiments were comparable, we observe systematically lower $\mathrm{K} \beta$ ' intensity for bridgmanite at ambient conditions (Figure 3a,b). Fe in bridgmanite is expected to be high-spin at 1 bar (McCammon 2006; McCammon et al. 2008; Lin et al. 2012). In a previous XRD study of bridgmanite synthesized from these compositions, the bridgmanite structure was not observed at ambient conditions, possibly due to amorphization (Dorfman et al. 2013). However, the XES for highspin amorphous almandine does not show any difference in the intensity of $\mathrm{K} \beta$ ' relative to other standards. If Fe-rich bridgmanite remains at ambient conditions, its distorted structure may also be responsible for the lower intensity of $\mathrm{K} \beta$ '. This may imply that structural differences between 
$(\mathrm{Mg}, \mathrm{Fe}) \mathrm{O}$ or other standards limit their applicability as high-spin standards for Fe-rich bridgmanite.

The total spin moment is calculated from XES data using an integrated difference between spectra and high- and low-spin references from Lin et al. (2010b), assuming a linear combination of high spin (total spin moment=2) and low spin (total spin moment=0) (Vankó et al. 2006; Mao et al. 2014). Differences between references from Lin et al (2010b) and secondary references are used to estimate uncertainty. The integrated absolute difference (IAD) method has been used in multiple previous studies of bridgmanite at mantle pressures (e.g. Lin et al. 2008, 2010a; Grocholski et al. 2009; Catalli et al. 2010, 2011; Mao et al. 2011) but suffers from underestimation of spin state due to pressure-induced broadening (Mao et al. 2014). Broadening effects can be corrected by using the integrated relative difference (IRD) method, which offsets decrease in $\mathrm{K} \beta$ ' with increase in intensity in the trough between $\mathrm{K} \beta$ ' and the main $\mathrm{K} \beta$ peak (Mao et al. 2014). For ( $\mathrm{Mg}, \mathrm{Fe}) \mathrm{O}$, the IRD method yields a decrease in the spin moment at pressures that agree with observations from XRD and Mössbauer spectroscopy (Lin et al. 2005; Mao et al. 2014). In IAD analysis, XES spectra are aligned to a common center of mass, normalized by area, and absolute values of differences are summed over a range from 7030 to $7070 \mathrm{eV}$. In IRD analysis, XES spectra are aligned to the main $\mathrm{K} \beta$ peak position, normalized by area, and differences are summed over only the $\mathrm{K} \beta$ ' portion of the spectra (up to $\sim 7056 \mathrm{eV}$ ). While the total spin moment obtained with the IAD method for Fe\#38 bridgmanite decreases by $\sim 1 / 3$ from 80-120 GPa (Figure 5a), with the IRD method the total spin moment for this material is approximately constant with pressure from 1 bar to $126 \mathrm{GPa}$ (Figure $5 \mathrm{~b}$ ). This suggests no spin transition occurs in this composition over this pressure range, and the small differences in XES data can be ascribed to pressure-induced broadening. 
The synchrotron Mössbauer spectrum recorded for the Fe\#38 sample at 126 GPa (Figure 4) can be used to identify the sites that contribute to the spin moment observed by XES. Fe\#38 bridgmanite exhibits a main doublet with quadrupole splitting (QS) of $4.15 \mathrm{~mm} / \mathrm{s}$ and center shift (CS) of $0.97 \mathrm{~mm} / \mathrm{s}$. This doublet matches previous observations of $\mathrm{Fe}^{2+}$ in the bridgmanite A-site identified as high spin (Hsu et al. 2010) or intermediate spin (Lin et al. 2008; McCammon et al. 2008). Another peak is observed at $-0.4 \mathrm{~mm} / \mathrm{s}$, which may either be a doublet with QS $\sim 0$ (McCammon et al. 2010) or one peak of a doublet with $\mathrm{CS}=1.21 \mathrm{~mm} / \mathrm{s}$ and $\mathrm{QS}=3.15 \mathrm{~mm} / \mathrm{s}$, where the other peak overlaps with the main doublet (Lin et al. 2008). The former possibility would match observations and predictions for low-spin $\mathrm{Fe}^{2+}$ (Hsu et al. 2010; McCammon et al. 2010), but this may be ruled out by XES indications of high spin and no transition. The latter doublet, shown in the fit in Figure 4, is within the range reported for high-spin $\mathrm{Fe}^{2+}$ (Dyar et al. 2006) or low-spin $\mathrm{Fe}^{3+}$ (Catalli et al. 2010), but low-spin $\mathrm{Fe}^{3+}$ would be expected to exhibit a lower value for CS (e.g. Pasternak et al. 2002), and again only the high-spin option is consistent with XES. Two high-spin $\mathrm{Fe}^{2+}$ sites are thus consistent with the synchrotron Mössbauer spectrum, no spin transition in Fe\#38 bridgmanite from 1 bar to $126 \mathrm{GPa}$, and predictions from DFT (Hsu et al. 2010).

The lower total spin moment of Fe\#74 bridgmanite observed at high pressure (Figure 5) indicates a spin transition does occur at lower pressures in more Fe-rich bridgmanite, as predicted by some DFT studies (Bengtson et al. 2008; Umemoto et al. 2008). At ambient conditions, the intensity of the $\mathrm{K} \beta$ ' peak and total spin moment for Fe\#38 and Fe\#74 bridgmanites are identical within uncertainty. At 78-88 GPa, immediately after synthesis, the total spin moment of Fe\#74 bridgmanite is $\sim 2 / 3$ that of Fe\#38 bridgmanite. As structures (Figure 1) and experimental conditions are similar for these three samples, the difference must be the onset of a spin 
transition in $\mathrm{Fe}^{2+}$ in $\mathrm{Fe} \# 74$ bridgmanite. The decrease in spin moment becomes significant between 40 and $68 \mathrm{GPa}$ in this composition.

Recent studies have attempted to identify structural differences in bridgmanite XRD due to spin transitions (Boffa Ballaran et al. 2012; Caracas et al. 2014). Relative to high-spin bridgmanite, low-spin bridgmanite was predicted and observed to exhibit additional diffraction peaks due to structural distortion and symmetry reduction (Caracas et al. 2014). However, all diffraction peaks for both Fe\#38 and Fe\#74 bridgmanite at 80-88 GPa match orthorhombic $\mathrm{GdFeO}_{3}$-type perovskite structure, with no extra low-symmetry peaks (Figure 1). Structural differences in lower-spin Fe\#74 bridgmanite at $88 \mathrm{GPa}$ are either not present or too subtle to observe. Both the spin transition and the structural distortion may be incomplete at the maximum pressure studied.

\section{Discussion}

In contrast to these observations, previous XES studies (Table 1) measured spin transitions in less Fe-rich bridgmanite over this pressure range, indicated by sharper changes in $\mathrm{K} \beta$ position and $\mathrm{K} \beta$ ' intensity (Badro et al. 2004; Catalli et al. 2010, 2011; Lin et al. 2010a; Fujino et al. 2012) or much lower K $\beta$ ' intensity ( $L i$ et al. 2004, 2006; Lin et al. 2008; Mao et al. 2011). These studies examined compositions ranging from 5-50\% $\mathrm{FeSiO}_{3}$ and estimated or measured $\mathrm{Fe}^{3+} / \mathrm{LFe}$ from $0-100 \%$. Differences in total spin moment observed in these studies are due in part to differences in abundances of $\mathrm{Fe}^{2+}$ and $\mathrm{A}$ - or $\mathrm{B}$-site $\mathrm{Fe}^{3+}$, which will each lose spin moment at different conditions. Of these sites, density functional theory predicts that only $\mathrm{B}$-site $\mathrm{Fe}^{3+}$ undergoes a spin transition within a mantle pressure range (Hsu et al. 2010, 2011). In

experiments, the simplest case is $\mathrm{Fe}_{2} \mathrm{O}_{3}$-bearing bridgmanite, which must contain $\mathrm{Fe}^{3+}$ in both $\mathrm{A}$ and B-sites. Based on both XES and T-SMS analyses, bridgmanite with $10 \% \mathrm{Fe}_{2} \mathrm{O}_{3}$ was 
observed to lose half its spin moment above $\sim 55 \mathrm{GPa}$, in good agreement with density functional theory (Catalli et al. 2010). Spin transitions in B-site $\mathrm{Fe}^{3+}$ have been reported at pressures as low as 13-24 GPa (Lin et al. 2012).

Pressure and temperature may increase the fraction of $\mathrm{B}$-site $\mathrm{Fe}^{3+}$ by migration of $\mathrm{Fe}^{3+}$ from the A site to the B site (Grocholski et al. 2009; Caracas 2010; Catalli et al. 2011; Hsu and Yu 2012; Fujino et al. 2014). For $\mathrm{FeAlO}_{3}$-bearing bridgmanite, whether the $\mathrm{Fe}^{3+}$ resides in $\mathrm{A}$ - or $\mathrm{B}$-site is generally unknown and has been suggested to change during heating/annealing (Caracas 2010; Hsu and $\mathrm{Yu}$ 2012). Diffusion of $\mathrm{Fe}^{3+}$ to the B-site may account for the transition observed in bridgmanites with $10-15 \% \mathrm{FeAlO}_{3}$ by Catalli et al. (2011) and Fujino et al. (2012) at 50-70 GPa, but does not appear to have affected other similar experiments despite annealing (NishioHamane et al. 2008; Potapkin et al. 2013).

For $\mathrm{FeSiO}_{3}$-bearing bridgmanites, density functional theory predicts a pressure-induced distortion in the bonding of high spin A-site $\mathrm{Fe}^{2+}$, resulting in a mixture of $\mathrm{A} 1$ and $\mathrm{A} 2$ sites with different nuclear energies, but no loss of spin moment (Hsu et al. 2010). Experimental observations of $\mathrm{FeSiO}_{3}$-bearing bridgmanites are even more complex because most analyses find some $\mathrm{Fe}^{3+}$, regardless of attempts to generate reducing conditions during synthesis (McCammon 1997; Frost and Langenhorst 2002; Frost et al. 2004; Grocholski et al. 2009). Thus spin transitions observed in bridgmanites synthesized from $\mathrm{Fe}^{2+}$-bearing starting materials may still occur in $\mathrm{Fe}^{3+}$ in the $\mathrm{B}$-site. In combination with diffusion of $\mathrm{A}$-site $\mathrm{Fe}^{3+}$, oxidation of $\mathrm{Fe}^{2+}$ may also increase the component of $\mathrm{B}$-site $\mathrm{Fe}^{3+}$ particularly during heating at deep lower mantle pressures (McCammon 1997; Frost et al. 2004; Zhang and Oganov 2006). A $10 \% \mathrm{FeSiO}_{3}$ composition examined with X-ray emission spectroscopy by Badro et al. (2004) with annealing showed loss of spin moment at 70 and $120 \mathrm{GPa}$, while unannealed samples showed only gradual 
changes ( $\mathrm{Li}$ et al. 2004, 2006; Jackson et al. 2005). A 25\% $\mathrm{FeSiO}_{3}$ composition exhibited X-ray emission spectra characteristic of a dominant low spin component from 80-135 GPa, but may have as much as $50 \% \mathrm{Fe}^{3+} / \Sigma \mathrm{Fe}$ (Mao et al. 2011). The $\mathrm{Fe}^{3+} / \Sigma \mathrm{Fe}$ ratio is most commonly determined at high pressure by T-SMS. To our knowledge, the only study to have reported $\mathrm{Fe}^{3+} / \Sigma \mathrm{Fe}$ ratio below detection limit was the Lin et al. (2008) combined T-SMS-XES study which, with McCammon et al. (2008), introduced the possibility of intermediate spin state $\mathrm{Fe}^{2+}$ in bridgmanite. These data have been reinterpreted to show either the two high-spin $\mathrm{Fe}^{2+}$ sites or a mixture of high-spin $\mathrm{Fe}^{2+}$ and low-spin $\mathrm{Fe}^{3+}$, consistent with theory (Lin et al. 2013).

The lack of a transition in Fe\#38 bridgmanite is consistent with high-spin Fe in our sample throughout the lower mantle pressure range. We expect that the dominant Fe species in the synthesized bridgmanites is $\mathrm{Fe}^{2+}$ in the A site (e.g. Vanpeteghem et al. 2006), as supported by our Mössbauer spectroscopy results for the Fe\#38 bridgmanite. Since typical measured $\mathrm{Fe}^{3+} / \Sigma \mathrm{Fe}$ ratios in bridgmanites synthesized from Al-free, Fe-rich compositions are $15 \%$ (e.g. Frost and Langenhorst 2002), minor amounts of $\mathrm{Fe}^{3+}$ may be present. As no annealing was performed on these samples after synthesis, changes in oxidation state or diffusion of Fe between sites on compression or decompression should be highly energetically unfavorable. Any $\mathrm{Fe}^{3+}$ in the B site would be expected to undergo a spin transition, but a few percent low-spin $\mathrm{Fe}^{3+}$ would not be detectable by either XES or Mössbauer spectroscopy in this work. In a similar experiment, Lin et al. (2010a) suggested a transition in Fe\#40 bridgmanite to a low or intermediate spin state based on analysis using the IAD method. Their calculated values for the total spin moment are in excellent agreement with our values for Fe\#38 bridgmanite using this method (Figure 5a). Consideration of pressure-induced broadening with the IRD method reveals no transition in Fe\#38 bridgmanite to at least $126 \mathrm{GPa}$. 
A transition in the Fe\#74 bridgmanite may be consistent with phase equilibria observed in the $(\mathrm{Mg}, \mathrm{Fe}) \mathrm{SiO}_{3}$ system. From $25-50 \mathrm{GPa}$, solubility of $\mathrm{FeSiO}_{3}$ in bridgmanite increases from 20 to $\sim 40 \% \mathrm{FeSiO}_{3}$ (e.g. Tange et al. 2009). Above $\sim 50 \mathrm{GPa}$, the bridgmanite to bridgmanite-plusoxides phase boundary must change slope to reach the higher solubility of $\mathrm{FeSiO}_{3}$ reported in recent experiments in the diamond anvil cell (Tateno et al. 2007; Dorfman et al. 2013): by 70 $\mathrm{GPa}$, the solubility of $\mathrm{FeSiO}_{3}$ increases to at least $75 \% \mathrm{FeSiO}_{3}$. These pressures and compositions correspond well to the observed onset of the spin transition in $\mathrm{Fe}^{2+}$.

Our observations match predictions from density functional theory studies that high Fe-content promotes the high-to-low spin transition in $(\mathrm{Mg}, \mathrm{Fe}) \mathrm{SiO}_{3}$ bridgmanite at lower pressures (Bengtson et al. 2008; Umemoto et al. 2008). The absolute transition pressure is highly dependent on the choice of exchange-correlation functional, but the overall trend is not. For $\left(\mathrm{Mg}_{0.25} \mathrm{Fe}_{0.75}\right) \mathrm{SiO}_{3}$ bridgmanite, the spin transition pressure was predicted to be 26-30 GPa (LDA method) or $80-106 \mathrm{GPa}$ (GGA method). For $\left(\mathrm{Mg}_{0.62} \mathrm{Fe}_{0.38}\right) \mathrm{SiO}_{3}$ bridgmanite, the transition pressure would be 55-75 GPA (LDA method) or 120-170 GPa (GGA method). The low transition pressures given by the LDA method are clearly inconsistent with our observations, but the GGA predictions are slightly higher than the pressure at which we observe the spin moment begins to decrease in our experiments. Our observations contradict the opposing prediction that the spin transition occurs at a higher pressure in $\mathrm{FeSiO}_{3}$ (Cohen et al. 1997; Stackhouse et al. 2007).

\section{Implications}

A lack of a sharp spin transition in $(\mathrm{Mg}, \mathrm{Fe}) \mathrm{SiO}_{3}$ bridgmanite is consistent with measured physical properties of this material. Equation of state measurements show no discontinuity in 
volume compression throughout the lower mantle pressure range (Lundin et al. 2008; Mao et al. 2011; Dorfman et al. 2013). The majority of experimental measurements and density functional theory calculations find that $\mathrm{Fe}^{2+}$-bearing bridgmanite, unlike low-spin $\mathrm{Fe}^{3+}$-bearing bridgmanite or low-spin $(\mathrm{Mg}, \mathrm{Fe}) \mathrm{O}$, is not significantly less compressible than $\mathrm{MgSiO}_{3}$-bridgmanite (Dorfman and Duffy 2014). These results support no discontinuity in the seismic properties of Fe-bearing bridgmanite in the lower mantle.

Differences in spin transition pressure in bridgmanite between this study and previous reports reflect differences in data processing (IAD vs. IRD), synthesis conditions (pressure, temperature, hydrostaticity of stress state, stability of heating, frequency of annealing), and composition (bulk $\mathrm{Fe}$-content, $\mathrm{Fe}^{3+} / \Sigma \mathrm{Fe}$, Al-content). Chemical heterogeneity in the deep lower mantle may result in regional differences in $\mathrm{Fe}$-spin due to differences in bulk $\mathrm{Al}$-content and $\mathrm{Fe}^{3+} / \Sigma \mathrm{Fe}$ ratio. These regional differences would have important effects on Earth's mantle via changes in chemical partitioning (Badro et al. 2004; Irifune et al. 2010; Fujino et al. 2014), increase in electrical conductivity (Ohta et al. 2010, 2012), thermal conductivity (Badro et al. 2004; Ohta et al. 2014) and density (Mao et al. 2011). The wide compositional range explored in this study provides improved constraints on the dependence of bridgmanite chemistry and properties on Fe-content which can be applied to chemical heterogeneities in the mantle.

Previous experiments have reached conflicting conclusions about the partitioning of iron between the bridgmanite and post-perovskite phases at the base of the mantle (Auzende et al. 2008; Hirose et al. 2008; Sinmyo et al. 2008; Sakai et al. 2009, 2010). If, as suggested by Hirose et al. (2008), iron favors the bridgmanite phase, then the beginning of the post-perovskite transition will correspond to an increase in iron content in bridgmanite, possibly increasing the post-perovskite transition pressure while decreasing the spin transition pressure in bridgmanite, 
promoting lower-spin ferrous iron in deep mantle bridgmanite. Conversely, if iron partitions into the post-perovskite phase (Auzende et al. 2008; Sakai et al. 2009), the post-perovskite transition will occur at shallower depths. If increasing Fe-content decreases the spin transition in postperovskite, the ferrous iron in the iron-rich post-perovskite may be expected to exhibit the lowspin state in Fe-rich heterogeneities.

An additional complication for deep lower mantle seismic structure is the possibility of multiple post-perovskite phases in Fe-bearing compositions (Yamanaka et al. 2012; Zhang et al. 2014). Zhang et al. (2014) have observed that at $\sim 95 \mathrm{GPa}$, Fe partitions strongly out of bridgmanite into a new "H-phase," of unknown structure and assumed $(\mathrm{Mg}, \mathrm{Fe}) \mathrm{SiO}_{3}$ stoichiometry. This observation conflicts with a large body of experimental work and has not been replicated by other experimenters. However, if the H-phase is the stable Fe-bearing silicate in the deep mantle, only a small amount of (high-spin) Fe will remain in bridgmanite. Phase transition boundaries between other post-perovskites and H-phase are unknown. Multiple other post-perovskite structures have been reported, depending on composition (Tschauner et al. 2008; Yamanaka et al. 2012). Phase transitions and partitioning between these post-perovskite potentially provide a mechanism for multiple discontinuities in the $\mathrm{D}$ " region.

In summary, this work adds to the growing experimental consensus that supports predictions by density functional theory of no spin transition in $\mathrm{Fe}^{2+}$-bearing bridgmanite over the lower mantle pressure range in likely mantle compositions. X-ray emission spectroscopy data show no change from 1 bar to $126 \mathrm{GPa}$ for $\left(\mathrm{Mg}_{0.61} \mathrm{Fe}_{0.38} \mathrm{Ca}_{0.01}\right) \mathrm{SiO}_{3}$ bridgmanite. A transition in $\left(\mathrm{Mg}_{0.25} \mathrm{Fe}_{0.74} \mathrm{Ca}_{0.01}\right) \mathrm{SiO}_{3}$ bridgmanites is consistent with predictions of a decrease in spin transition pressure at high Fe-content. 


\section{Acknowledgments}

We thank the Ecole polytechnique fédérale de Lausanne for financial support for this project. J. Badro acknowledges the financial support of the UnivEarthS Labex program at Sorbonne Paris Cité (ANR-10-LABX-0023 and ANR-11-IDEX-0005-02). F. Nabiei, H. Piet, R. Gaal, and I. Blanchard participated in beamline operations. X-ray emission spectroscopy experiments were performed at HPCAT (Sector 16), Advanced Photon Source (APS), Argonne National Laboratory and GALAXIES, Synchrotron SOLEIL. HPCAT operations are supported by DOENNSA under Award No. DE-NA0001974 and DOE-BES under Award No. DE-FG0299ER45775, with partial instrumentation funding by NSF. The Advanced Photon Source is a U.S. Department of Energy (DOE) Office of Science User Facility operated for the DOE Office of Science by Argonne National Laboratory under Contract No. DE-AC02-06CH11357. We acknowledge SOLEIL for provision of synchrotron radiation facilities (Proposal ID 20130184) and we would like to thank B. Lassalle and J. Ablett for assistance in using beamline GALAXIES. V. Potapkin, I. Kupenko, C. A. McCammon and L. Dubrovinsky assisted with synchrotron Mössbauer spectroscopy and interpretation. We thank E. E. Alp and L. Gao for assistance with Mössbauer spectroscopy of starting materials. Conventional Mössbauer spectroscopy at the Advanced Photon Source (APS), Argonne National Laboratory is supported by the Consortium for Materials Properties Research in Earth Sciences (COMPRES). Supporting XRD experiments were performed on the ID27 beamline at the European Synchrotron Radiation Facility (ESRF), Grenoble, France and GeoSoilEnviroCARS (Sector 13) at the APS. We are grateful to M. Mezouar at ESRF for providing assistance in using beamline ID27. We thank V. B. Prakapenka for support at 13-ID-B. GeoSoilEnviroCARS is supported by 
the National Science Foundation - Earth Sciences (EAR-0622171), Department of Energy Geosciences (DE-FG02-94ER14466) and the State of Illinois.

\section{References}

Akahama, Y., and Kawamura, H. (2006) Pressure calibration of diamond anvil Raman gauge to 310 GPa. Journal of Applied Physics, 100, 043516-4.

Auzende, A.-L., Badro, J., Ryerson, F.J., Weber, P.K., Fallon, S.J., Addad, A., Siebert, J., and Fiquet, G. (2008) Element partitioning between magnesium silicate perovskite and ferropericlase: New insights into bulk lower mantle geochemistry. Earth and Planetary Science Letters, 269, 164-174.

Badro, J., Fiquet, G., Guyot, F., Rueff, J.-P., Struzhkin, V.V., Vankó, G., and Monaco, G. (2003) Iron Partitioning in Earth's Mantle: Toward a Deep Lower Mantle Discontinuity. Science, 300, 789-791.

Badro, J., Rueff, J.-P., Vanko, G., Monaco, G., Fiquet, G., and Guyot, F. (2004) Electronic Transitions in Perovskite: Possible Nonconvecting Layers in the Lower Mantle. Science, 305, 383-386.

Bengtson, A., Persson, K., and Morgan, D. (2008) Ab initio study of the composition dependence of the pressure-induced spin crossover in perovskite $\left(\mathrm{Mg}_{1-\mathrm{x}}, \mathrm{Fe}_{\mathrm{x}}\right) \mathrm{SiO}_{3}$. Earth and Planetary Science Letters, 265, 535-545.

Bengtson, A., Li, J., and Morgan, D. (2009) Mössbauer modeling to interpret the spin state of iron in $(\mathrm{Mg}, \mathrm{Fe}) \mathrm{SiO}_{3}$ perovskite. Geophysical Research Letters, 36, $5 \mathrm{PP}$.

Boffa Ballaran, T., Kurnosov, A., Glazyrin, K., Frost, D.J., Merlini, M., Hanfland, M., and Caracas, R. (2012) Effect of chemistry on the compressibility of silicate perovskite in the lower mantle. Earth and Planetary Science Letters, 333-334, 181-190.

Bradley, J.A., Moore, K.T., Lipp, M.J., Mattern, B.A., Pacold, J.I., Seidler, G.T., Chow, P., Rod, E., Xiao, Y., and Evans, W.J. (2012) $4 f$ electron delocalization and volume collapse in praseodymium metal. Physical Review B, 85, 100102.

Caracas, R. (2010) Spin and structural transitions in $\mathrm{AlFeO}_{3}$ and $\mathrm{FeAlO}_{3}$ perovskite and postperovskite. Physics of the Earth and Planetary Interiors.

Caracas, R., Ozawa, H., Hirose, K., Ishii, H., Hiraoka, N., Ohishi, Y., and Hirao, N. (2014) Identifying the spin transition in $\mathrm{Fe}^{2+}$-rich $\mathrm{MgSiO}_{3}$ perovskite from X-ray diffraction and vibrational spectroscopy. American Mineralogist, 99, 1270-1276. 
Catalli, K., Shim, S.-H., Prakapenka, V.B., Zhao, J., Sturhahn, W., Chow, P., Xiao, Y., Liu, H., Cynn, H., and Evans, W.J. (2010) Spin state of ferric iron in $\mathrm{MgSiO}_{3}$ perovskite and its effect on elastic properties. Earth and Planetary Science Letters, 289, 68-75.

Catalli, K., Shim, S.-H., Dera, P., Prakapenka, V.B., Zhao, J., Sturhahn, W., Chow, P., Xiao, Y., Cynn, H., and Evans, W.J. (2011) Effects of the $\mathrm{Fe}^{3+}$ spin transition on the properties of aluminous perovskite - New insights for lower-mantle seismic heterogeneities. Earth and Planetary Science Letters, 310, 293-302.

Cohen, R.E., Mazin, I.I., and Isaak, D.G. (1997) Magnetic Collapse in Transition Metal Oxides at High Pressure: Implications for the Earth. Science, 275, 654-657.

Dorfman, S.M., and Duffy, T.S. (2014) Effect of Fe-enrichment on seismic properties of perovskite and post-perovskite in the deep lower mantle. Geophysical Journal International, 197, 910-919.

Dorfman, S.M., Meng, Y., Prakapenka, V.B., and Duffy, T.S. (2013) Effects of Fe-enrichment on the equation of state and stability of $(\mathrm{Mg}, \mathrm{Fe}) \mathrm{SiO}_{3}$ perovskite. Earth and Planetary Science Letters, 361, 249-257.

Dorfman, S.M., Potapkin, V., Kupenko, I., Chumakov, A.I., Nabiei, F., Magrez, A., Dubrovinsky, L., McCammon, C.A., and Gillet, P. (2014) Complex Effects of Alumina/Silica on Ferric/Ferrous Iron in Earth's Lower Mantle. In American Geophysical Union Fall Meeting. Presented at the 2014 AGU Fall Meeting, San Francisco.

Dyar, M.D., Agresti, D.G., Schaefer, M.W., Grant, C.A., and Sklute, E.C. (2006) Mössbauer spectroscopy of Earth and planetary materials. Annual Review of Earth and Planetary Sciences, 34, 83-125.

Fei, Y., Zhang, L., Corgne, A., Watson, H., Ricolleau, A., Meng, Y., and Prakapenka, V. (2007) Spin transition and equations of state of $(\mathrm{Mg}, \mathrm{Fe}) \mathrm{O}$ solid solutions. Geophysical Research Letters, 34, L17307.

Frost, D.J., and Langenhorst, F. (2002) The effect of $\mathrm{Al}_{2} \mathrm{O}_{3}$ on Fe-Mg partitioning between magnesiowüstite and magnesium silicate perovskite. Earth and Planetary Science Letters, 199, 227-241.

Frost, D.J., Liebske, C., Langenhorst, F., McCammon, C.A., Trønnes, R.G., and Rubie, D.C. (2004) Experimental evidence for the existence of iron-rich metal in the Earth's lower mantle. Nature, 428, 409-412.

Fujino, K., Nishio-Hamane, D., Seto, Y., Sata, N., Nagai, T., Shinmei, T., Irifune, T., Ishii, H., Hiraoka, N., Cai, Y.Q., and others (2012) Spin transition of ferric iron in Al-bearing Mgperovskite up to $200 \mathrm{GPa}$ and its implication for the lower mantle. Earth and Planetary Science Letters, 317-318, 407-412. 
Fujino, K., Nishio-Hamane, D., Nagai, T., Seto, Y., Kuwayama, Y., Whitaker, M., Ohfuji, H., Shinmei, T., and Irifune, T. (2014) Spin transition, substitution, and partitioning of iron in lower mantle minerals. Physics of the Earth and Planetary Interiors, 228, 186-191.

Grocholski, B., Shim, S.H., Sturhahn, W., Zhao, J., Xiao, Y., and Chow, P.C. (2009) Spin and valence states of iron in $\left(\mathrm{Mg}_{0.8} \mathrm{Fe}_{0.2}\right) \mathrm{SiO}_{3}$ perovskite. Geophysical Research Letters, 36, L24303.

Hirose, K., Takafuji, N., Fujino, K., Shieh, S.R., and Duffy, T.S. (2008) Iron partitioning between perovskite and post-perovskite: A transmission electron microscope study. American Mineralogist, 93, 1678-1681.

Hsu, H., and Yu, Y.G. (2012) Spin crossover of iron in aluminous $\mathrm{MgSiO}_{3}$ perovskite and postperovskite. Earth and Planetary Science Letters, 359-360, 34-39.

Hsu, H., Umemoto, K., Blaha, P., and Wentzcovitch, R.M. (2010) Spin states and hyperfine interactions of iron in $(\mathrm{Mg}, \mathrm{Fe}) \mathrm{SiO}_{3}$ perovskite under pressure. Earth and Planetary Science Letters, 294, 19-26.

Hsu, H., Blaha, P., Cococcioni, M., and Wentzcovitch, R.M. (2011) Spin-State Crossover and Hyperfine Interactions of Ferric Iron in $\mathrm{MgSiO}_{3}$ Perovskite. Physical Review Letters, 106, 118501.

Irifune, T., Shinmei, T., McCammon, C.A., Miyajima, N., Rubie, D.C., and Frost, D.J. (2010) Iron Partitioning and Density Changes of Pyrolite in Earth's Lower Mantle. Science, 327, $193-195$.

Jackson, J.M., Sturhahn, W., Shen, G., Zhao, J., Hu, M.Y., Errandonea, D., Bass, J.D., and Fei, Y. (2005) A synchrotron Mössbauer spectroscopy study of $(\mathrm{Mg}, \mathrm{Fe}) \mathrm{SiO}_{3}$ perovskite up to 120 GPa. American Mineralogist, 90, 199-205.

Li, J., Struzhkin, V.V., Mao, H. -k., Shu, J., Hemley, R.J., Fei, Y., Mysen, B., Dera, P., Prakapenka, V.B., and Shen, G. (2004) Electronic spin state of iron in lower mantle perovskite. Proceedings of the National Academy of Sciences, 101, 14027-14030.

Li, J., Sturhahn, W., Jackson, J., Struzhkin, V., Lin, J., Zhao, J., Mao, H., and Shen, G. (2006) Pressure effect on the electronic structure of iron in $(\mathrm{Mg}, \mathrm{Fe})(\mathrm{Si}, \mathrm{Al}) \mathrm{O}_{3}$ perovskite: a combined synchrotron Mössbauer and X-ray emission spectroscopy study up to $100 \mathrm{GPa}$. Physics and Chemistry of Minerals, 33, 575-585.

Lin, J.-F., Struzhkin, V.V., Jacobsen, S.D., Hu, M.Y., Chow, P., Kung, J., Liu, H., Mao, H., and Hemley, R.J. (2005) Spin transition of iron in magnesiowüstite in the Earth's lower mantle. Nature, 436, 543-551.

Lin, J.-F., Watson, H., Vanko, G., Alp, E.E., Prakapenka, V.B., Dera, P., Struzhkin, V.V., Kubo, A., Zhao, J., McCammon, C., and others (2008) Intermediate-spin ferrous iron in lowermost mantle post-perovskite and perovskite. Nature Geoscience, 1, 688-691. 
Lin, J.-F., Speziale, S., Prakapenka, V., Dera, P., Lavina, B., and Watson, H. (2010a) Highpressure X-ray diffraction and X-ray emission studies on iron-bearing silicate perovskite under high pressures. High Pressure Research, 30, 230-237.

Lin, J.-F., Mao, Z., Jarrige, I., Xiao, Y., Chow, P., Okuchi, T., Hiraoka, N., and Jacobsen, S.D. (2010b) Resonant X-ray emission study of the lower-mantle ferropericlase at high pressures. American Mineralogist, 95, 1125-1131.

Lin, J.-F., Alp, E.E., Mao, Z., Inoue, T., McCammon, C., Xiao, Y., Chow, P., and Zhao, J. (2012) Electronic spin states of ferric and ferrous iron in the lower-mantle silicate perovskite. American Mineralogist, 97, 592-597.

Lin, J.-F., Speziale, S., Mao, Z., and Marquardt, H. (2013) Effects of the electronic spin transitions of iron in lower mantle minerals: Implications for deep mantle geophysics and geochemistry. Reviews of Geophysics, 51.

Lundin, S., Catalli, K., Santillán, J., Shim, S.-H., Prakapenka, V.B., Kunz, M., and Meng, Y. (2008) Effect of $\mathrm{Fe}$ on the equation of state of mantle silicate perovskite over 1 Mbar. Physics of the Earth and Planetary Interiors, 168, 97-102.

Mao, Z., Lin, J.F., Jacobs, C., Watson, H.C., Xiao, Y., Chow, P., Alp, E.E., and Prakapenka, V.B. (2010) Electronic spin and valence states of $\mathrm{Fe}$ in $\mathrm{CaIrO}_{3}$-type silicate postperovskite in the Earth's lowermost mantle. Geophysical Research Letters, 37, 4 PP.

Mao, Z., Lin, J.F., Scott, H.P., Watson, H.C., Prakapenka, V.B., Xiao, Y., Chow, P., and McCammon, C. (2011) Iron-rich perovskite in the Earth's lower mantle. Earth and Planetary Science Letters, 309, 179-184.

Mao, Z., Lin, J.-F., Yang, J., Wu, J., Watson, H.C., Xiao, Y., Chow, P., and Zhao, J. (2014) Spin and valence states of iron in Al-bearing silicate glass at high pressures studied by synchrotron Mössbauer and X-ray emission spectroscopy. American Mineralogist, 99, 415-423.

Mattila, A., Rueff, J.-P., Badro, J., Vankó, G., and Shukla, A. (2007) Metal-ligand interplay in strongly correlated oxides: A parametrized phase diagram for pressure-induced spin transitions. Physical Review Letters, 98, 196404.

McCammon, C., Kantor, I., Narygina, O., Rouquette, J., Ponkratz, U., Sergueev, I., Mezouar, M., Prakapenka, V., and Dubrovinsky, L. (2008) Stable intermediate-spin ferrous iron in lower-mantle perovskite. Nature Geoscience, 1, 684-687.

McCammon, C.A. (1997) Perovskite as a possible sink for ferric iron in the lower mantle. Nature, 387, 694-696.

(2006) Microscopic Properties to Macroscopic Behaviour: The Influence of Iron Electronic State. J Mineral Petrol Sci, 101, 130-144. 
McCammon, C.A., Dubrovinsky, L., Narygina, O., Kantor, I., Wu, X., Glazyrin, K., Sergueev, I., and Chumakov, A.I. (2010) Low-spin $\mathrm{Fe}^{2+}$ in silicate perovskite and a possible layer at the base of the lower mantle. Physics of the Earth and Planetary Interiors, 180, 215-221.

Nishio-Hamane, D., Seto, Y., Fujino, K., and Nagai, T. (2008) Effect of $\mathrm{FeAlO}_{3}$ incorporation into $\mathrm{MgSiO}_{3}$ perovskite on the bulk modulus of perovskite. Physics of the Earth and Planetary Interiors, 166, 219-225.

Ohta, K., Hirose, K., Shimizu, K., Sata, N., and Ohishi, Y. (2010) The electrical resistance measurements of $(\mathrm{Mg}, \mathrm{Fe}) \mathrm{SiO}_{3}$ perovskite at high pressures and implications for electronic spin transition of iron. Physics of the Earth and Planetary Interiors, 180, 154158.

Ohta, K., Yagi, T., Taketoshi, N., Hirose, K., Komabayashi, T., Baba, T., Ohishi, Y., and Hernlund, J. (2012) Lattice thermal conductivity of $\mathrm{MgSiO}_{3}$ perovskite and postperovskite at the core-mantle boundary. Earth and Planetary Science Letters, 349-350, $109-115$.

Ohta, K., Yagi, T., and Hirose, K. (2014) Thermal diffusivities of $\mathrm{MgSiO}_{3}$ and Al-bearing $\mathrm{MgSiO}_{3}$ perovskites. American Mineralogist, 99, 94-97.

Pasternak, M.P., Xu, W.M., Rozenberg, G.K., and Taylor, R.D. (2002) Electronic, Magnetic and Structural Properties of the $\mathrm{RFeO}_{3}$ Antiferromagnetic-Perovskites at Very High Pressures. In Symposium D - Perovskite Materials Vol. 718.

Peng, G., Wang, X., Randall, C.R., Moore, J.A., and Cramer, S.P. (1994) Spin selective X-ray absorption spectroscopy: Demonstration using high resolution $\mathrm{Fe} \mathrm{K} \beta$ fluorescence. Applied Physics Letters, 65, 2527-2529.

Potapkin, V., Chumakov, A.I., Smirnov, G.V., Celse, J.-P., Rüffer, R., McCammon, C., and Dubrovinsky, L. (2012) The ${ }^{57}$ Fe Synchrotron Mössbauer Source at the ESRF. Journal of Synchrotron Radiation, 19, 559-569.

Potapkin, V., McCammon, C., Glazyrin, K., Kantor, A., Kupenko, I., Prescher, C., Sinmyo, R., Smirnov, G.V., Chumakov, A.I., Rüffer, R., and others (2013) Effect of iron oxidation state on the electrical conductivity of the Earth's lower mantle. Nature Communications, $4,1427$.

Prescher, C., McCammon, C., and Dubrovinsky, L. (2012) MossA: a program for analyzing energy-domain Mössbauer spectra from conventional and synchrotron sources. Journal of Applied Crystallography, 45, 329-331.

Rueff, J.-P., Kao, C.-C., Struzhkin, V.V., Badro, J., Shu, J., Hemley, R.J., and Mao, H.K. (1999) Pressure-Induced High-Spin to Low-Spin Transition in FeS Evidenced by X-Ray Emission Spectroscopy. Physical Review Letters, 82, 3284.

Rueff, J.-P., Ablett, J.M., Céolin, D., Prieur, D., Moreno, T., Balédent, V., Lassalle-Kaiser, B., Rault, J.E., Simon, M., and Shukla, A. (2015) The GALAXIES beamline at the SOLEIL 
synchrotron: inelastic X-ray scattering and photoelectron spectroscopy in the hard X-ray range. Journal of Synchrotron Radiation, 22.

Rüffer, R., and Chumakov, A.I. (1996) Nuclear Resonance Beamline at ESRF. Hyperfine Interactions, 97-98, 589-604.

Sakai, T., Ohtani, E., Terasaki, H., Sawada, N., Kobayashi, Y., Miyahara, M., Nishijima, M., Hirao, N., Ohishi, Y., and Kikegawa, T. (2009) Fe-Mg partitioning between perovskite and ferropericlase in the lower mantle. American Mineralogist, 94, 921-925.

Sakai, T., Ohtani, E., Terasaki, H., Miyahara, M., Nishijima, M., Hirao, N., Ohishi, Y., and Sata, N. (2010) Fe-Mg partitioning between post-perovskite and ferropericlase in the lowermost mantle. Physics and Chemistry of Minerals, 37, 487-496.

Sinmyo, R., Hirose, K., Nishio-Hamane, D., Seto, Y., Fujino, K., Sata, N., and Ohishi, Y. (2008) Partitioning of iron between perovskite/postperovskite and ferropericlase in the lower mantle. Journal of Geophysical Research, 113, 11 PP.

Speziale, S., Milner, A., Lee, V.E., Clark, S.M., Pasternak, M.P., and Jeanloz, R. (2005) Iron spin transition in Earth's mantle. Proceedings of the National Academy of Sciences of the United States of America, 102, 17918-17922.

Stackhouse, S., Brodholt, J.P., and Price, G.D. (2007) Electronic spin transitions in iron-bearing $\mathrm{MgSiO}_{3}$ perovskite. Earth and Planetary Science Letters, 253, 282-290.

Tange, Y., Takahashi, E., Nishihara, Y., Funakoshi, K., and Sata, N. (2009) Phase relations in the system $\mathrm{MgO}-\mathrm{FeO}-\mathrm{SiO}_{2}$ to $50 \mathrm{GPa}$ and $2000^{\circ} \mathrm{C}$ : An application of experimental techniques using multianvil apparatus with sintered diamond anvils. Journal of Geophysical Research, 114, B02214.

Tateno, S., Hirose, K., Sata, N., and Ohishi, Y. (2007) Solubility of $\mathrm{FeO}$ in (Mg,Fe) $\mathrm{SiO}_{3}$ perovskite and the post-perovskite phase transition. Physics of the Earth and Planetary Interiors, 160, 319-325.

Tschauner, O., Kiefer, B., Liu, H., Sinogeikin, S., Somayazulu, M., and Luo, S.-N. (2008) Possible structural polymorphism in Al-bearing magnesium silicate post-perovskite. American Mineralogist, 93, 533-539.

Tsuchiya, T., Wentzcovitch, R.M., da Silva, C.R., and de Gironcoli, S. (2006) Spin transition in magnesiowüstite in Earth's lower mantle. Physical Review Letters, 96, 198501.

Umemoto, K., Wentzcovitch, R.M., Yu, Y.G., and Requist, R. (2008) Spin transition in (Mg, $\mathrm{Fe}) \mathrm{SiO}_{3}$ perovskite under pressure. Earth and Planetary Science Letters, 276, 198-206.

Umemoto, K., Hsu, H., and Wentzcovitch, R.M. (2010) Effect of site degeneracies on the spin crossovers in $(\mathrm{Mg}, \mathrm{Fe}) \mathrm{SiO}_{3}$ perovskite. Physics of the Earth and Planetary Interiors, 180, 209-214. 
Vankó, G., Neisius, T., Molnár, G., Renz, F., Karpati, S., Shukla, A., and de Groot, F.M.F. (2006) Probing the $3 \mathrm{~d}$ spin momentum with X-ray emission spectroscopy: The case of molecular-spin transitions. The Journal of Physical Chemistry B, 110, 11647-11653.

Vanpeteghem, C.B., Angel, R.J., Ross, N.L., Jacobsen, S.D., Dobson, D.P., Litasov, K.D., and Ohtani, E. (2006) Al, Fe substitution in the $\mathrm{MgSiO}_{3}$ perovskite structure: A single-crystal X-ray diffraction study. Physics of the Earth and Planetary Interiors, 155, 95-103.

Yamanaka, T., Hirose, K., Mao, W.L., Meng, Y., Ganesh, P., Shulenburger, L., Shen, G., and Hemley, R.J. (2012) Crystal structures of $\left(\mathrm{Mg}_{1-\mathrm{x}}, \mathrm{Fe}_{\mathrm{x}}\right) \mathrm{SiO}_{3}$ postperovskite at high pressures. Proceedings of the National Academy of Sciences, 109, 1035-1040.

Zhang, F., and Oganov, A.R. (2006) Valence state and spin transitions of iron in Earth's mantle silicates. Earth and Planetary Science Letters, 249, 436-443.

Zhang, L., Meng, Y., Yang, W., Wang, L., Mao, W.L., Zeng, Q.-S., Jeong, J.S., Wagner, A.J., Mkhoyan, K.A., Liu, W., and others (2014) Disproportionation of $(\mathrm{Mg}, \mathrm{Fe}) \mathrm{SiO}_{3}$ perovskite in Earth's deep lower mantle. Science, 344, 877-882. 


\section{Figure captions}

Figure 1: X-ray diffraction patterns of synthesized Fe-bearing bridgmanites at $300 \mathrm{~K}$ and reference stick pattern for orthorhombic bridgmanite. Gray starred reference sticks are additional peaks predicted by Caracas et al. (2014) for low-spin bridgmanite. X-ray wavelength is $\lambda=0.3344$ for these measurements.

Figure 2: Experimental geometries for X-ray emission spectroscopy at a) HPCAT and b) GALAXIES beamlines.

Figure 3: X-ray emission spectra and difference spectra relative to low-spin reference observed on decompression at APS 16-ID-D (a,b) and compression at SOLEIL GALAXIES (c) for $\left(\mathrm{Mg}_{0.25} \mathrm{Fe}_{0.74} \mathrm{Ca}_{0.01}\right) \mathrm{SiO}_{3}$ (a) and $\left(\mathrm{Mg}_{0.61} \mathrm{Fe}_{0.38} \mathrm{Ca}_{0.01}\right) \mathrm{SiO}_{3}$ (b,c) compositions (colored lines). Reference spectra for $\left(\mathrm{Mg}_{0.75} \mathrm{Fe}_{0.25}\right) \mathrm{O}$ at ambient conditions (high spin, solid black line) and 90 GPa (low spin, dashed black line) (Lin et al. 2010b) and almandine-composition glass and enstatite measured at ambient conditions at HPCAT and GALAXIES, respectively, are also shown (high-spin, bold black line).

Figure 4: Energy-domain synchrotron Mössbauer spectrum recorded over $\sim 18$ hrs at beamline ID18 of the European Synchrotron Radiation Source for Fe38-bridgmanite at 126 GPa after XES experiment. The fit is a two-site model with a Lorentzian profile (Prescher et al. 2012). Site 1 has center shift of $0.98 \mathrm{~mm} / \mathrm{s}$, quadrupole splitting of $4.18 \mathrm{~mm} / \mathrm{s}$, and intensity of $55 \%$, and site 2 has center shift of $1.21 \mathrm{~mm} / \mathrm{s}$, quadrupole splitting of $3.15 \mathrm{~mm} / \mathrm{s}$, and intensity of $45 \%$. Sites are identified by analogy to experiments on ${ }^{57} \mathrm{Fe}$-enriched bridgmanite samples (Lin et al. 2008; Dorfman et al. 2014). 
Figure 5: a) Total spin moment calculated from integrated absolute difference (Vankó et al. 2006) between measured spectra and reference high- and low-spin spectra (Lin et al. 2010b). Black triangles represent $\left(\mathrm{Mg}_{0.25} \mathrm{Fe}_{0.74} \mathrm{Ca} 0.01\right) \mathrm{SiO}_{3}$-composition bridgmanite while gray triangles represent $\left(\mathrm{Mg}_{0.61} \mathrm{Fe}_{0.38} \mathrm{Ca}_{0.01}\right) \mathrm{SiO}_{3}$-composition bridgmanite. Gray circles represent measurements of $\left(\mathrm{Mg}_{0.60} \mathrm{Fe}_{0.40}\right) \mathrm{SiO}_{3}$-composition bridgmanite by Lin et al. (2010a). Direction of triangle points indicates compression (APS 16-ID-D) or decompression (SOLEIL GALAXIES). A loss of spin moment is observed above $40 \mathrm{GPa}$ for $74 \% \mathrm{FeSiO}_{3}$. b) Total spin moment calculated from integrated relative difference method (Mao et al. 2014). 
Table 1 : Summary of previous observations of spin transitions in bridgmanite in multianvil or diamond anvil cell (DAC) experiments using X-ray emission spectroscopy (XES), conventional Mössbauer spectroscopy (MS), time-domain synchrotron Mössbauer spectroscopy (T-SMS), energy-domain synchrotron Mössbauer spectroscopy (E-SMS), X-ray diffraction (XRD) and electrical resistivity (ER).

\begin{tabular}{|c|c|c|c|c|c|}
\hline $\begin{array}{l}\text { Spin } \\
\text { transition }\end{array}$ & Compositions & Synthesis & Annealing & Methods & References \\
\hline $\begin{array}{l}\text { None/no } \\
\text { effect }\end{array}$ & $\begin{array}{l}6-40 \% \mathrm{FeSiO}_{3} \\
\left(0-80 \% \mathrm{Fe}^{3+}\right)\end{array}$ & $\begin{array}{l}25-88 \mathrm{GPa} \\
\text { (multianvil or } \\
\text { DAC) }\end{array}$ & $\begin{array}{l}\text { Each step } \\
\text { or none }\end{array}$ & $\begin{array}{l}\text { E-SMS, } \\
\text { ER, XES, } \\
\text { XRD }\end{array}$ & $\begin{array}{l}\text { Potapkin et al. } \\
\text { (2013), This study }\end{array}$ \\
\hline $\begin{array}{l}\text { Gradual } \\
\text { decrease }\end{array}$ & $\begin{array}{l}9-14 \% \\
\mathrm{FeSiO}_{3}, 10 \% \\
\mathrm{FeAlO}_{3}(15- \\
\left.70 \% \mathrm{Fe}^{3+}\right)\end{array}$ & $\begin{array}{l}25-35 \mathrm{GPa} \\
\text { (multianvil or } \\
\text { DAC) }\end{array}$ & $\begin{array}{l}\text { None or } \\
<1000 \mathrm{~K}\end{array}$ & $\begin{array}{l}\text { MS, } \\
\text { XES, T- } \\
\text { SMS }\end{array}$ & $\begin{array}{l}\text { Li et al. (2004, } \\
\text { 2006), McCammon } \\
\text { et al. (2008) }\end{array}$ \\
\hline $\begin{array}{l}\text { Transition } \\
\text { below } 50 \\
\text { GPa } \\
\end{array}$ & $\begin{array}{l}10 \% \mathrm{FeSiO}_{3} \\
10 \% \mathrm{FeAlO}_{3} \\
\left(25-70 \% \mathrm{Fe}^{3+}\right) \\
\end{array}$ & $\begin{array}{l}\text { 23-26 GPa } \\
\text { (multianvil) }\end{array}$ & None & $\begin{array}{l}\text { T-SMS, } \\
\text { XES, } \\
\text { XRD }\end{array}$ & $\begin{array}{l}\text { Li et al. (2006), Lin } \\
\text { et al. (2012) }\end{array}$ \\
\hline $\begin{array}{l}\text { Gradual } \\
\text { transition } \\
\text { ends at 50- } \\
70 \text { GPa }\end{array}$ & $\begin{array}{l}5-50 \% \mathrm{FeSiO}_{3} \\
\left(40 \% \mathrm{Fe}^{3+} \text { or }\right. \\
\text { unknown) }\end{array}$ & $\begin{array}{l}26-93 \mathrm{GPa} \\
\mathrm{GPa} \\
\text { (multianvil or } \\
\text { DAC) }\end{array}$ & None & $\begin{array}{l}\text { T-SMS, } \\
\text { XES, } \\
\text { XRD }\end{array}$ & $\begin{array}{l}\text { Jackson et al. } \\
(2005) \text {, Caracas et } \\
\text { al. }(2014)\end{array}$ \\
\hline $\begin{array}{l}\text { Sharp } \\
\text { transition } \\
\text { at 50-85 } \\
\text { GPa }\end{array}$ & $\begin{array}{l}10-40 \% \\
\mathrm{FeSiO}_{3}, 10 \% \\
\mathrm{Fe}_{2} \mathrm{O}_{3}, 10- \\
15 \% \mathrm{FeAlO} \\
(10-100 \% \\
\mathrm{Fe}^{3+} \text { or } \\
\text { unknown) }\end{array}$ & $\begin{array}{l}25-110 \mathrm{GPa} \\
\text { (multianvil or } \\
\text { DAC) }\end{array}$ & $\begin{array}{l}\text { Each step } \\
\text { or none }\end{array}$ & $\begin{array}{l}\text { ER, XES, } \\
\text { XRD, T- } \\
\text { SMS }\end{array}$ & $\begin{array}{l}\text { Badro et al. (2004), } \\
\text { Grocholski et al. } \\
(2009) \text {, Catalli et al. } \\
(2010,2011) \text {, Lin et } \\
\text { al. (2010a), Ohta et } \\
\text { al. (2010), Fujino et } \\
\text { al. (2012) }\end{array}$ \\
\hline $\begin{array}{l}\text { Gradual } \\
\text { transition } \\
\text { begins at } \\
\mathbf{5 0 - 7 0 ~ G P a ~}\end{array}$ & $\begin{array}{l}74 \% \mathrm{FeSiO}_{3} \\
\text { (unknown } \\
\mathrm{Fe}^{3+} \text { ) }\end{array}$ & $\begin{array}{l}88 \mathrm{GPa} \\
(\mathrm{DAC})\end{array}$ & None & $\begin{array}{l}\text { XES } \\
\text { XRD }\end{array}$ & This study \\
\hline $\begin{array}{l}\text { Sharp } \\
\text { transition } \\
\text { at 120-135 } \\
\text { GPa }\end{array}$ & $\begin{array}{l}10-40 \% \\
\mathrm{FeSiO}_{3}(10- \\
20 \% \mathrm{Fe}^{3+} \text { or } \\
\text { unknown })\end{array}$ & $\begin{array}{l}30-120 \mathrm{GPa} \\
(\mathrm{DAC})\end{array}$ & $\begin{array}{l}\text { Each step } \\
\text { or none }\end{array}$ & $\begin{array}{l}\text { XES, } \\
\text { XRD, T- } \\
\text { SMS }\end{array}$ & $\begin{array}{l}\text { (Badro et al. 2004), } \\
\text { Lin et al. (2010a), } \\
\text { McCammon et al. } \\
(2010)\end{array}$ \\
\hline
\end{tabular}




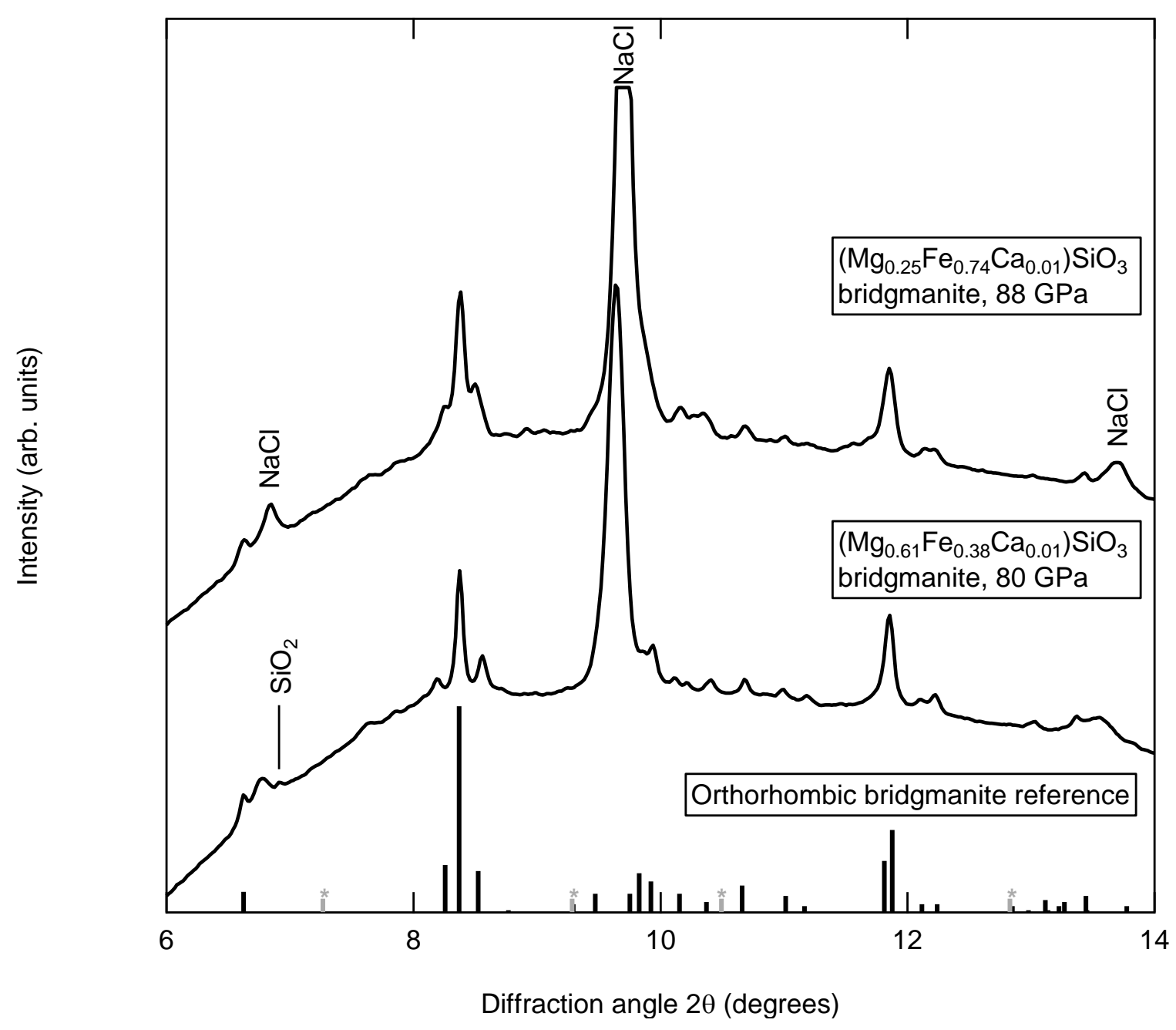

Figure 1 


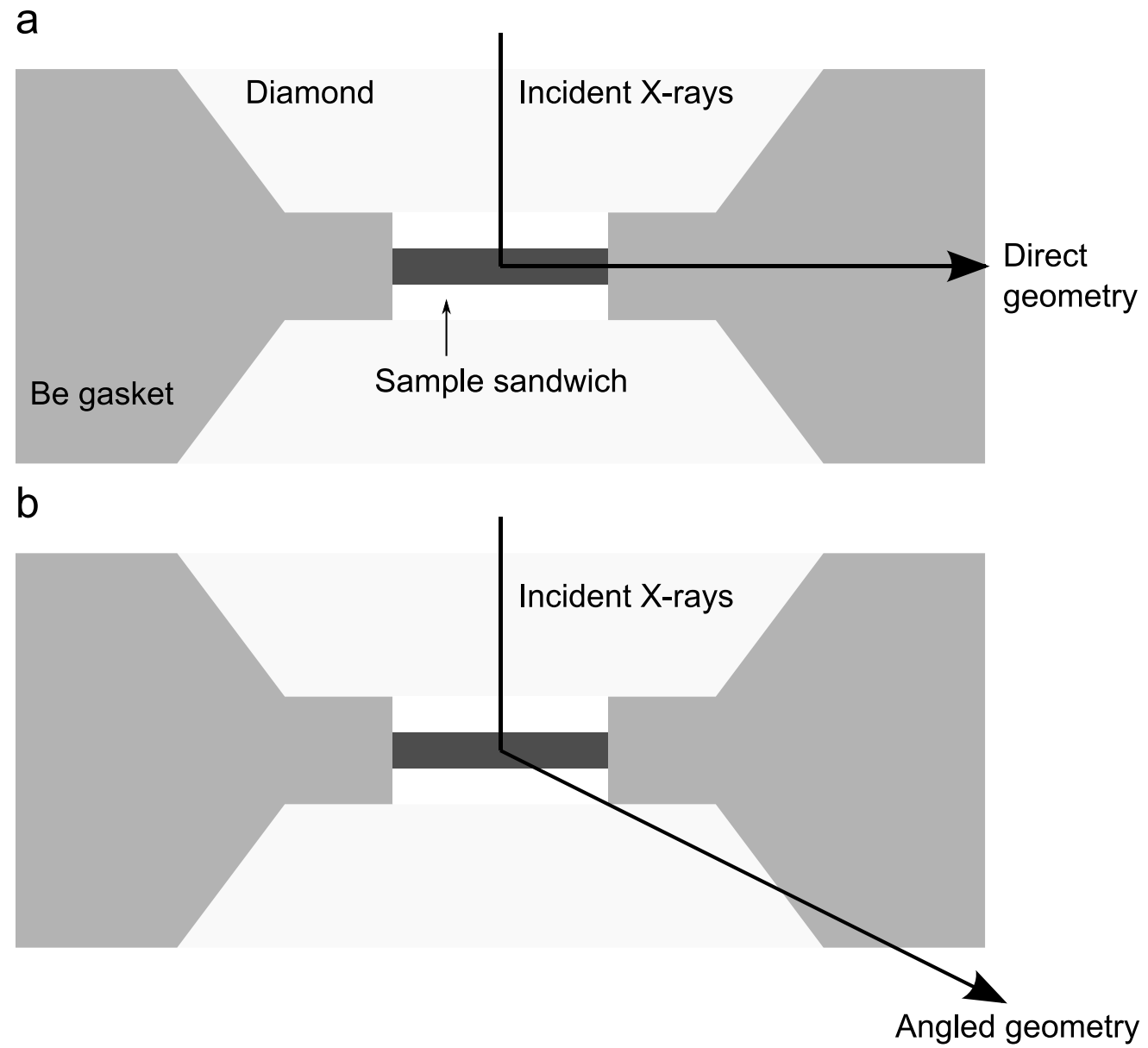

Figure 2 


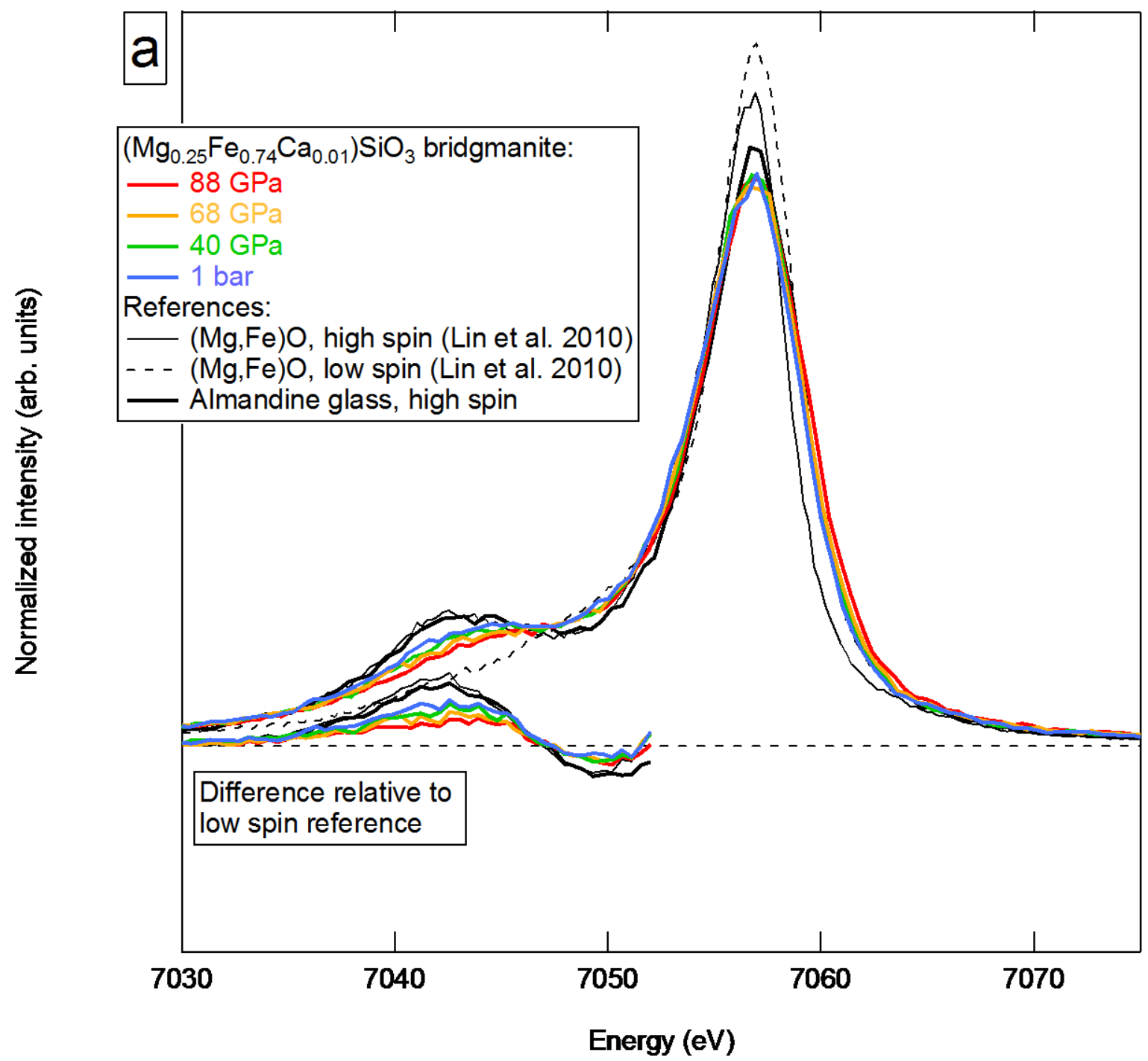




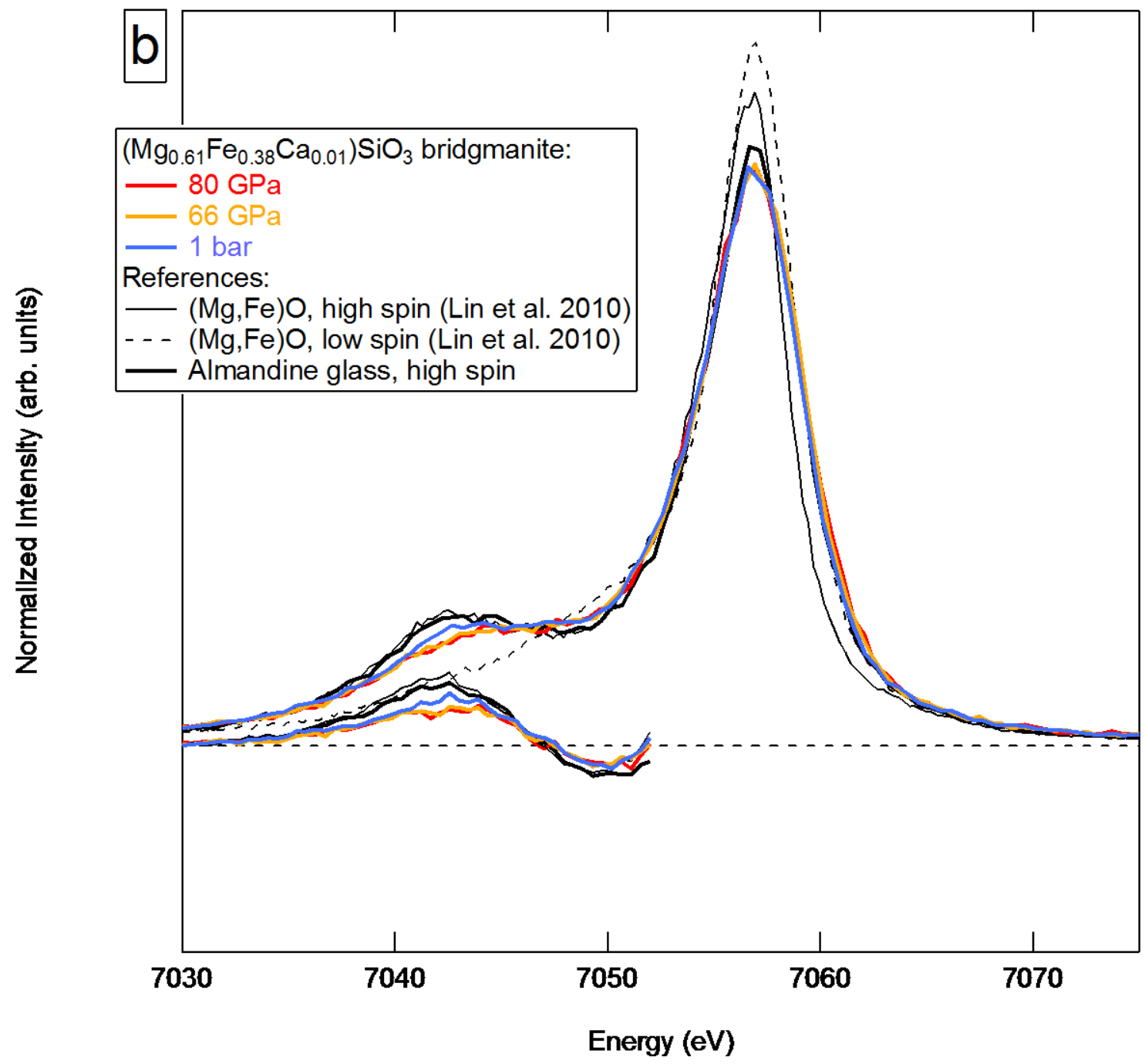




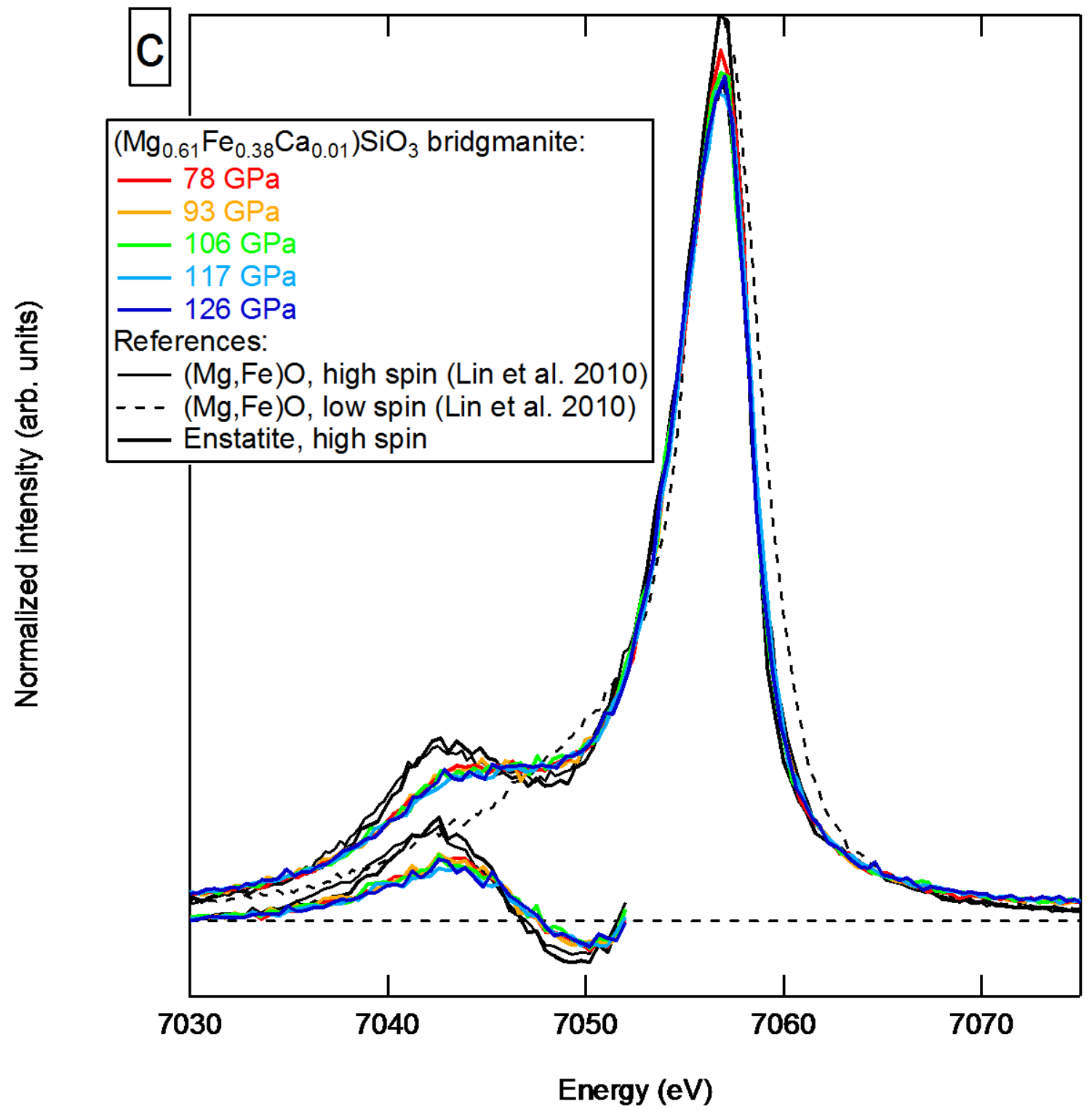

Figure 3 


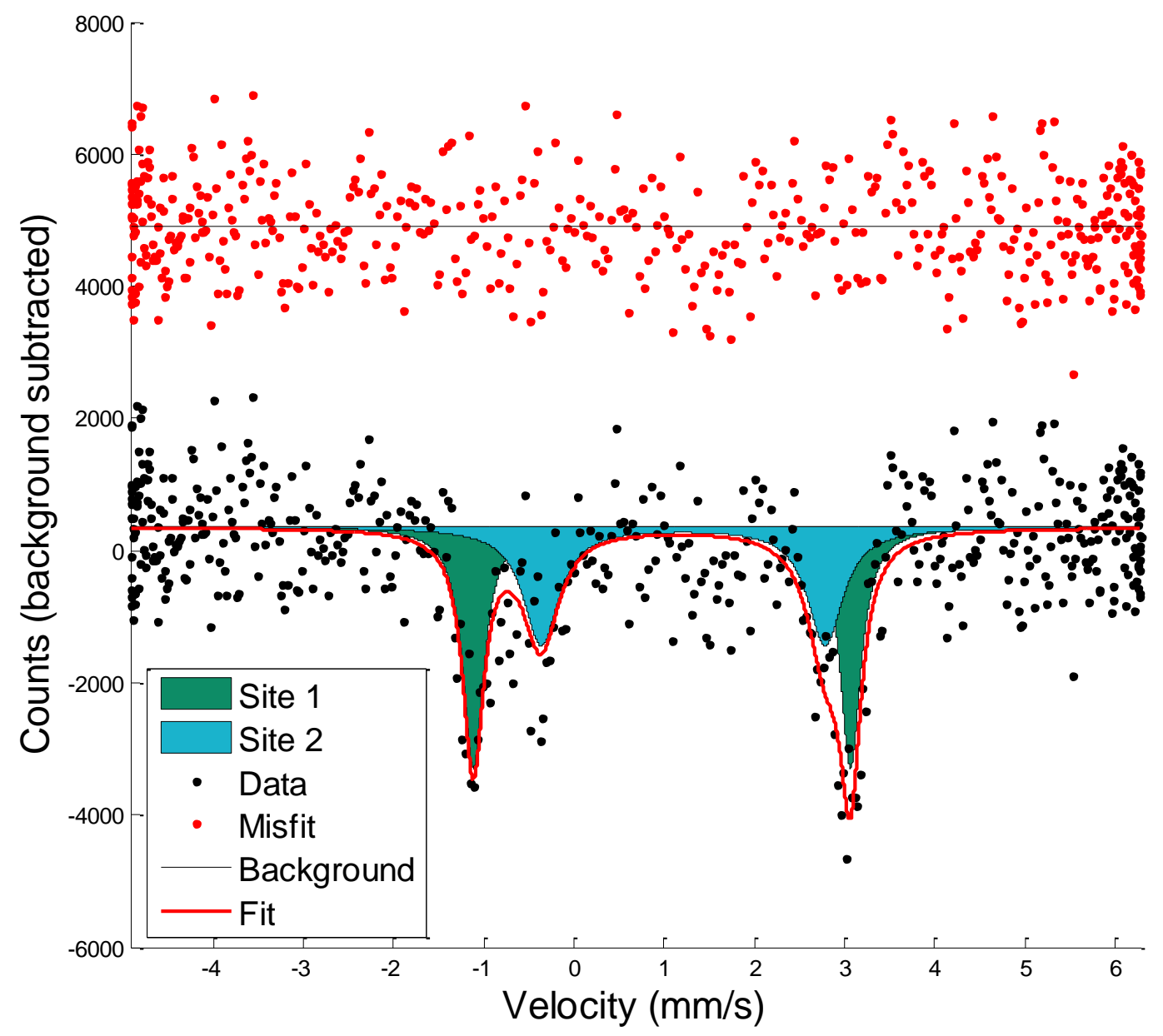

Figure 4 

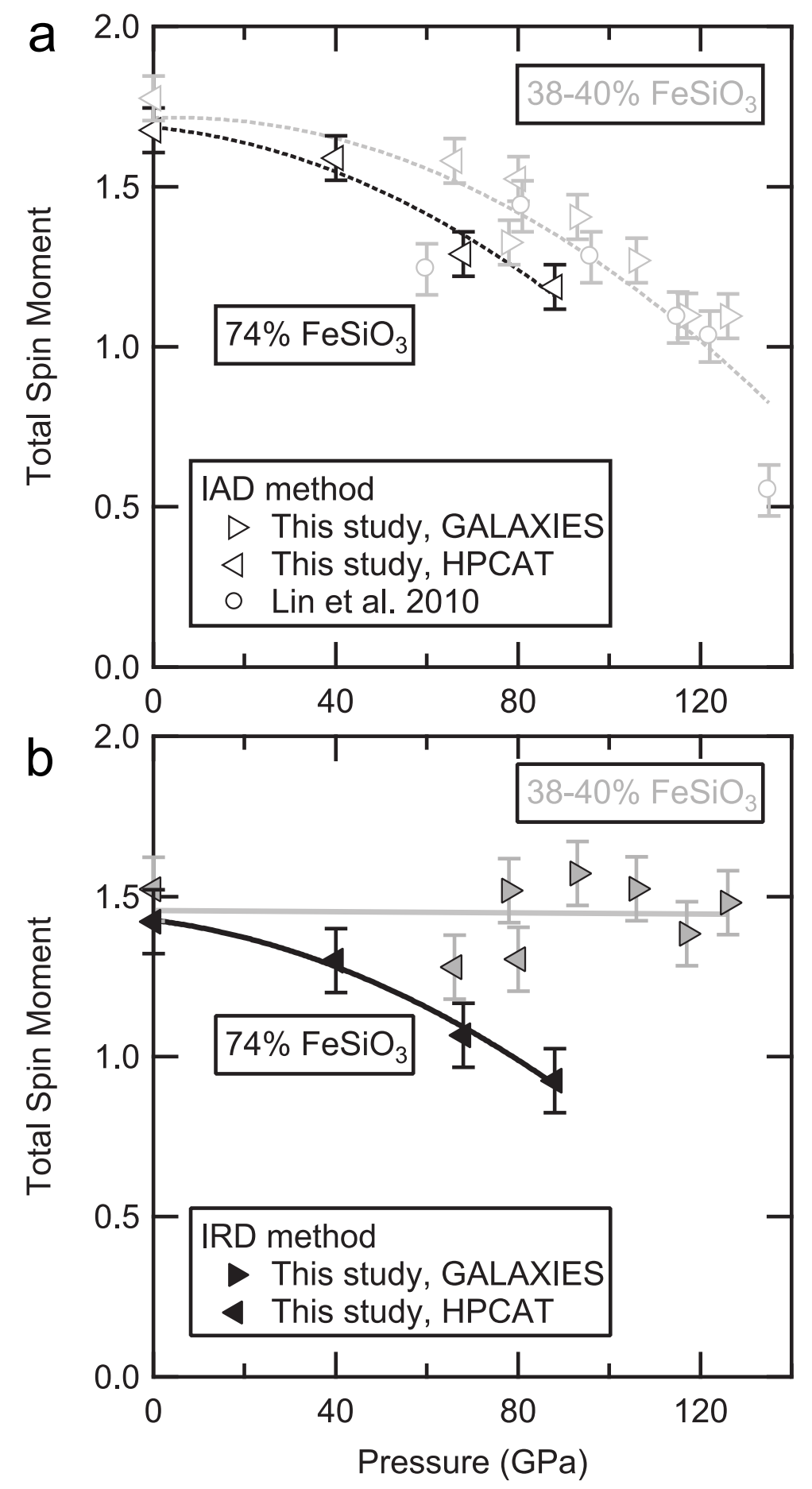

Figure 5 